\title{
Geschäftsbericht 2018 der FMH Services Genossenschaft
}

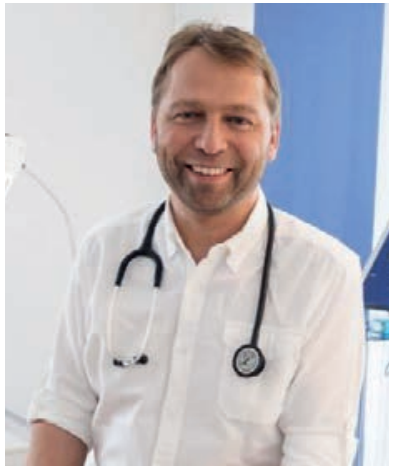

Dr. med., MLaw Beat Bumbacher Präsident der Verwaltung FMH Services Genossenschaft

Im operativen Bereich hat die FMH Services Genossenschaft im Jahr 2018 sehr erfolgreich gearbeitet. Das regionale Netzwerk wurde weiter konsolidiert und ausgebaut, das Dienstleistungsangebot erweitert. Wir freuen uns, dass unsere Angebote von Ärztinnen und Ärzten wahrgenommen werden; sehr positiv sind auch wichtige Referenzprojekte und die Berichte und Wahrnehmungen in den Medien. Dies zeigt uns, dass sich die Beziehungen $\mathrm{zu}$ unserer Kundschaft weiter vertiefen. Denn wir tun alles dafür, der Ärzteschaft möglichst viel Zeit zu verschaffen, damit sie auf die Bedürfnisse ihrer Patientinnen und Patienten eingehen kann.
Nach den in den Vorjahren realisierten positiven Ergebnissen sorgten die erheblichen Finanzmarktturbulenzen im vergangenen Dezember für Einbussen; dies führte in der Erfolgsrechnung der Genossenschaft zu nicht realisierten Verlusten auf Anlagen. Zum Jahresbeginn ist dann an den Finanzmärkten der umgekehrte Effekt eingetreten, was die Zahlen wieder in einem besseren Licht erscheinen lässt. Zum Stichtag 31.12.2018 waren die negativen Entwicklungen an den Finanzmärkten allerdings nicht wettzumachen. Die Bilanz der FMH Services Genossenschaft weist eine absolut solide Struktur aus. Der Geschäftsbericht 2018 kann auf unserer Website www.fmhservices.ch eingesehen werden.

Ich danke allen Beteiligten unserer Organisation, darin eingeschlossen sämtliche Mitglieder unseres engmaschigen Partnernetzes, für ihre erfolgreiche Tätigkeit im vergangenen Jahr.

Ihnen, liebe Genossenschafterinnen und Genossenschafter, danke ich für Ihre Treue und Kundschaft. Wir freuen uns, dass wir Sie unterstützen und Ihnen dabei ein verlässlicher Partner sein dürfen.

\section{Rapport de gestion 2018 de la coopérative FMH Services}

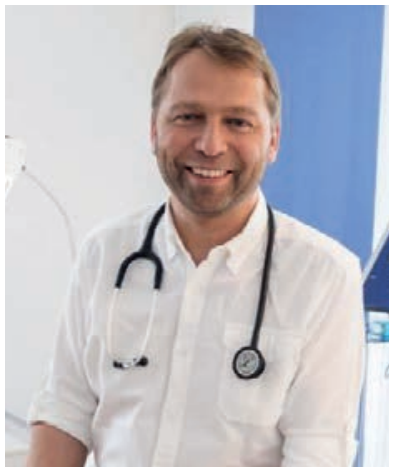

Dr méd. Beat Bumbacher MLaw, Président du conseil d'administration de la coopérative FMH Services

Dans le domaine opérationnel, la coopérative FMH Services a réalisé de très bons résultats. Le réseau régional a été consolidé et élargi, l'offre de prestations complétée. Nous nous réjouissons que nos offres soient sollicitées par les médecins. Les projets de référence ainsi que les articles et notre image dans les médias sont d'autres éléments très positifs. Cela nous montre que les relations avec nos clients se renforcent continuellement. Car nous mettons tout en œuvre pour permettre au corps médical de consacrer plus de temps aux besoins de leurs patientes et patients.
Après les résultats positifs réalisés au cours des années précédentes, les turbulences considérables sur les marchés financiers en décembre dernier se sont traduites par des pertes. Il a donc fallu imputer des pertes non réalisées sur les placements dans le compte de résultat de la coopérative. Au début de l'année, l'effet contraire s'est produit sur les marchés financiers, ce qui laisse à nouveau apparaître les chiffres sous un jour plus favorable. A la date de référence du 31.12.2018, les évolutions négatives sur les marchés financiers n'ont cependant pas pu être compensées. Le bilan de la coopérative FMH Services demeure néanmoins solide. Le rapport de gestion 2018 peut être consulté sur www.fmhservices.ch.

Je tiens à remercier ici toutes les parties prenantes dans notre organisation, ainsi que tous les membres de notre réseau de partenaires pour leur engagement tout au long de l'année.

Chers sociétaires, je vous remercie de votre fidélité et de votre confiance. Nous continuerons de tout mettre en œuvre pour vous soutenir et rester, pour vous, un partenaire fiable. 